\title{
Free Energy
}

National Cancer Institute

\section{Source}

National Cancer Institute. Free Energy. NCI Thesaurus. Code C18218.

A thermodynamic term used to describe the energy that may be extracted from a system at constant temperature and pressure. In biological systems the most important relationship is: $\mathrm{G}=\mathrm{RT} \ln (\mathrm{Keq})$, where Keq is an equilibrium constant. 